admiration for a man whose natural inclination was towards the scholar's life, yet who was drawn into the practice of medicine and the mitigation of suffering by his pity for and desire to help poor suffering England. Maybe destiny decided that his unique relation to the sovereign as personal medical attendant and instructor of the royal children, along with an unusual gift for diplomacy and the tactful handling of proud men and their dependants, fitted him for a special role in the progress of medical affairs. At any rate, through such patronage and access to the throne, Linacre and his little band of devoted medical colleagues initiated a revolution in the organization of the profession and sounded a call for higher standards in training and ethics that has constituted the grandeur of the Royal College of Physicians throughout its long history. The fact that he advocated the out-of-date scholastic approach to medicine by his devotion to Galen and the ancient writers, and that he ignored the signals of a new science which had already appeared above the horizon, has its warning for those of us who engage our lives in the detection and prevention of the ravages of disease. We, too, are faced by the tremendous upsurge of science in general and of scientific medicine in particular. The challenge is, I believe, a much more serious one in medicine than in other disciplines, for it is all too easy for the doctor to take refuge in the time-honoured beliefs of the past and rest content with delegating, often with scarcely concealed contempt and patronage, the duty of investigation to a little band of dedicated workers. No one who has come through an illness, least of all myself, will decry the God-given qualities that warm the personality of the born clinician and make him an ever-present help in times of trouble. But these gifts are still menaced by pretence and humbug which is not confined to the ignorant and indolent but threatens the seats of the mighty and successful.

We who spend much of our lives in training the oncoming member of our profession must be especially alert to challenge and combat the shoddy and the sham, the facile explanations, the dead-hand of plausible empiricism. Like Linacre, we are standing at the portal of a dazzling, unbounded world of medical science, entry to which calls for courage, imagination, and the highest qualities that bless the human spirit. May we not be found wanting when the opportunity of playing our part comes our way.

Figs. 1-3 are reproduced by kind permission of the Editor and Publishers of the fournal of Pathology and Bacteriology.

\section{REFERENCES}

Mehrotra, R. M. L. (1953). F. Path. Bact., 66, 79.

Mitchell, R. J. (1935). Eng. Hist. Rev., October, p. 696.

Spector, W. G., and Willoughby, D. A. (1963). Bact. Rev., 27, 117.

Thorndike, L. (1928). Ann. med. Hist., 10, 270.

Vasari, G. (1960). In Lives of the Artists, edited by Betty Buroughs, p. 260. Allen and Unwin, London.

\title{
Intrauterine Transfusion for Haemolytic Disease of the Newborn
}

\author{
C. A. HOLMAN,* M.B., M.R.c.P. ; JADWIGA KARNICKI, $†$ M.B., CH.B., F.R.C.o.G.
}

Brit. med. F., 1964, 2, 594-597

Despite advances in the treatment of haemolytic disease of the newborn, the only remedy against stillbirth has been premature delivery, which is ineffective before 32-34 weeks' gestation and in which prematurity is a considerable additional hazard. Liley (1963b) has reported successful intraperitoneal transfusion of the foetus in utero and has shown that Bevis's (1953, 1956) method of spectrophotometric examination of the amniotic fluid is a useful guide to the selection of patients who are likely to have stillborn or severely affected foetuses (Liley, 1961, 1963a). Since then McCrostie (1964) has reported another successful case.

In this hospital we deliver each year nearly 200 mothers who have rhesus iso-immunization, and despite selective premature delivery, exchange transfusion, and attempted resuscitation of hydropic foetuses, we have a stillbirth rate of about $8 \%$ and a neonatal death rate of about $6 \%$. These new techniques offer the prospect of more exact selection of affected infants, a reduction in the degree of prematurity, and the possibility of preventing hydrops foetalis. We have now performed intrauterine transfusion on six occasions and feel that our experience might be of some value to others attempting this form of treatment.

\section{Case 1}

Gravida-5 aged 26. Estimated date of delivery 13 January 1964. Blood group A rr ; husband's group $O R_{1} R_{1}$. First pregnancy,

\footnotetext{
* Consultant Pathologist, Lewisham Group Laboratory, London. + Consultant Gynaecologist and Obstetrician, Lewisham Hospital,
}

1958: miscarried at 10 weeks. Second pregnancy, 1958: a healthy 6-lb. (2,720-g.) infant at 39 weeks; no antibodies found. Third pregnancy, 1960: spontaneous delivery at 33 weeks of an infant weighing $2 \mathrm{lb} .11 \mathrm{oz}$. (1,220 g.) who was not affected with haemolytic disease, and who survived and is normal. Fourth pregnancy, 1961: spontaneous rupture of membranes at 31 weeks; anti-D antibodies of titre 1:8,000 discovered; patients transferred to Lewisham and delivered spontaneously of hydropic infant who died 80 minutes later.

Present Pregnancy, 1963.-Anti-D titre 1;8,000 in albumin; at 31 weeks spectrophotometric examination showed a very high peak at $450 \mathrm{~m} \mu$ (optical density 0.85 ), indicating very severe haemolytic disease. The patient and her husband had heard that intrauterine blood transfusion could increase the chance of the baby's survival and requested that we attempt it. She was a slim woman and the fotal parts were easily felt.

The technique advised by Liley was followed exactly. On 14 November 1963, at 32 weeks, $20 \mathrm{ml}$. of $76 \%$ Urografin was injected into the uterine cavity and an antero-posterior and a lateral $x$-ray film were taken. Five hours later a further lateral $x$-ray film did not show any Urografin in the foetal gut. The foetus was clearly hydropic (Fig. 1) and we presume that this prevented it from swallowing. Under local anaesthesia an $8-\mathrm{cm}$. Tuohy needle was introduced into the uterine cavity, the stylet was removed, and a syringe with saline was attached. As the needle advanced inside the uterine cavity, saline was injected. It was hoped that when the needle met with the foetal abdomen there would be resistance to the injected fluid, which would indicate the position of the needle, and that when the needle entered the foetal abdomen ascitic fluid would be aspirated. After several unsuccessful attempts this technique was abandoned. The needle was advanced under the direct feel of the hand, and this showed that the texture of the tissue through which the needle goes could be distinctly felt. When the 
needles was thought to be in the foetal abdominal cavity a plastic catheter $30 \mathrm{~cm}$. long was pushed through the needle, $3 \mathrm{ml}$. of Urografin injected, and a lateral film taken. The $x$-ray film (Fig. 2) clearly

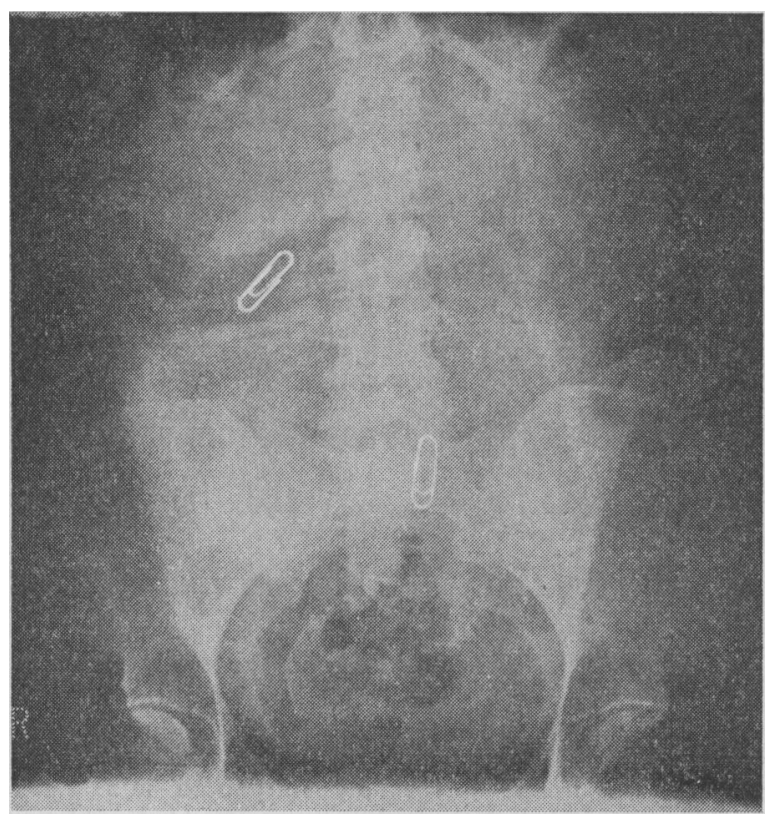

Fig. 1.-Case 1. Antero-posterior $x$-ray film. Paper-clips mark the position of foetal parts. The foetus is hydropic.

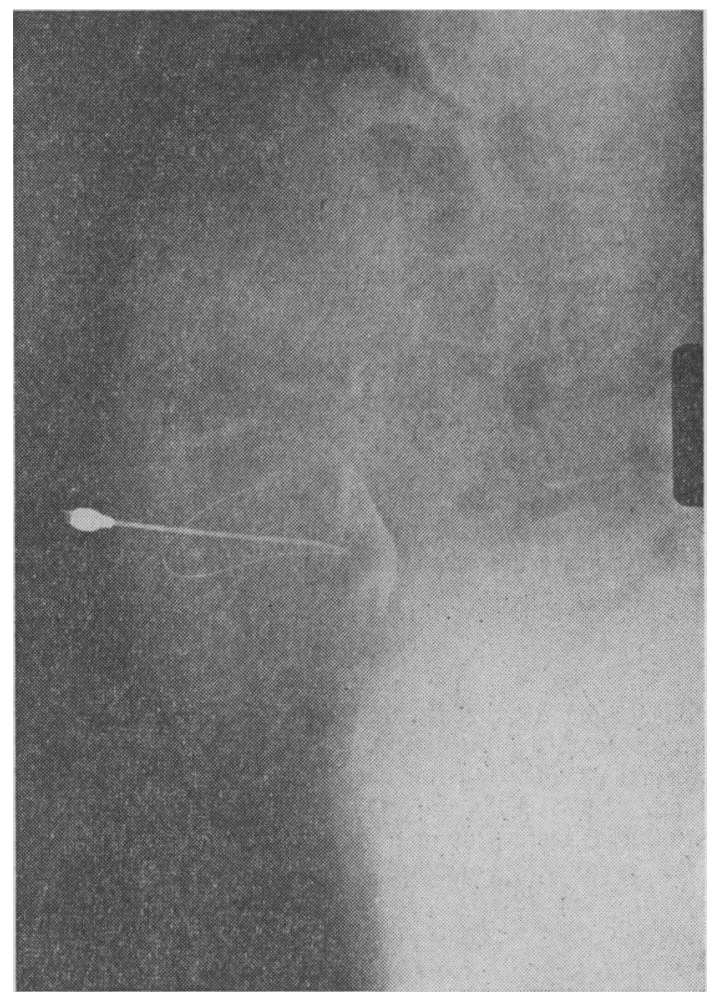

FIg. 2.-Case 1. Radiograph showing that the needle is inside the foetal abdomen; the Urografin outlines the abdominal cavity.

showed coils of the tube and Urografin collected in the lower part of the baby's abdomen. This proved that the catheter was in the right place, and $100 \mathrm{ml}$. of packed, Rh-negative, group A red cells was injected within 30 minutes.

A few hours before the above procedure was started the patient had a brown show, giving warning of premature delivery, and she was delivered of a live, hydropic, female infant eight hours after the transfusion. The infant's respiration was gasping and, despite immediate exchange transfusion and aspiration of blood and ascitic fluid from the peritoneal cavity, she died 50 minutes after birth. The infant's cord bilirubin was $2 \mathrm{mg} . / 100 \mathrm{ml}$., the haemoglobin determination was unfortunately overlooked, and it was undoubtedly quite low. The red cells were a mixture of donor $\mathrm{A} \mathrm{Rh}$-negative and foetal $\mathrm{A}_{1} \mathrm{Rh}$-positive, Coombs positive cells and these were estimated by separation with antisera and measurement of foetal haemoglobin : this showed that approximately $65 \%$ of the circulating red cells were donor cells. Post-mortem examination showed that two punctures had been made into the peritoneal cavity and that one of these had passed under the capsule of the liver and caused a small haematoma; three other punctures had entered the subcutaneous tissues. There were no other findings except those associated with hydrops foetalis.

\section{Case 2}

Gravida-3 aged 30. Estimated date of delivery 10 March 1964. Blood group $\mathrm{O} r r$; husband's group $\mathrm{O} \mathbf{R}_{2} \mathbf{R}_{0}$. First pregnancy, 1957: a full-time normal infant weighing $6 \mathrm{lb} .13 \mathrm{oz} .(3,090 \mathrm{~g}$.). Second pregnancy, 1958: anti-D antibodies to a titre of $1: 2,000$ in albumin led to delivery at $36 \frac{1}{2}$ weeks of an infant with severe haemolytic disease ; birth weight $5 \mathrm{lb} .11 \mathrm{oz}$. (2,580 g.). Her cord haemoglobin was $53 \%$ and bilirubin $8 \mathrm{mg} . / 100 \mathrm{ml}$. She received two exchange transfusions, survived, and is normal.

Present Pregnancy, 1964.-At two months the albumin titre was 2,000 and at 28 weeks it was 4,000. Amniocentesis was performed at 32 weeks and showed a high pigment concentration (optical density 0.125 at $450 \mathrm{~m} \mu$ ). This implied that the prognosis for the baby was very poor, and, clinically, hydrops was suspected. The situation was explained to the patient and her husband and the possibility of intrauterine transfusion was discussed: they agreed that it should be attempted.

On 29 February 1964, when the patient was 33 weeks 4 days pregnant, an intrauterine blood transfusion was performed. The technique used this time was simplified. Only one antero-posterior

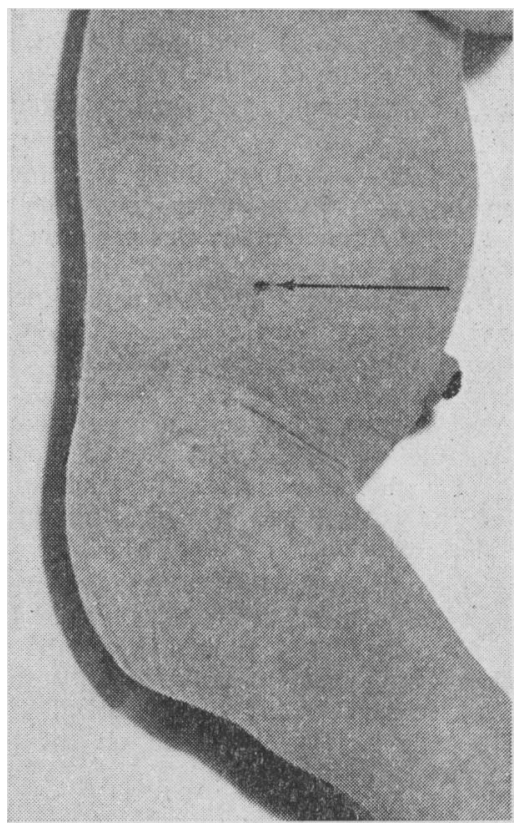

FIG. 3.-Case 2. Photograph showing the place where the needle went through the abdominal wall.

$x$-ray film of the abdomen was taken to identify the position of the baby with paper-clip markings.

Under local anaesthesia a Tuohy needle was introduced into the uterine cavity and liquor was aspirated to assess the position of the needle ; the baby's parts were felt with the needle, which, being blunt, could be safely used to probe the uterine cavity without fear of damaging the foetus. The resistance of the baby's abdomen was felt and then the needle was pushed firmly into the foetal abdominal cavity. A polythene catheter (Charles Thackray No. 49) was introduced through the needle and $2 \mathrm{ml}$. of Urografin was injected. A lateral $x$-ray film showed the position of the tube in the foetal peritoneal cavity and the Urografin outlining the lower part of the foetal abdomen. The needle was then withdrawn and the catheter left in the foetal peritoneal cavity. Then $100 \mathrm{ml}$. of packed group $\mathrm{O}, \mathrm{Rh}$-negative red cells was injected into the foetal peritoneal 
cavity; this took 60 minutes. The catheter was withdrawn and a dressing applied. During the procedure a foetal heart monitor showed that the foetal heart had maintained a steady rhythm and had increased only slightly at the time when the needle was being pushed into the baby's abdomen.

As pre-operative treatment the mother was given $150 \mathrm{mg}$. of pethidine and 1 mega unit of penicillin; post-operatively tetracycline $500 \mathrm{mg}$. eight-hourly was given for three days. Antibiotics were not introduced into the uterine cavity.

After this blood transfusion the patient felt very well and noticed that foetal movements increased very rapidly. She was discharged on the third day and returned a week later for observation. She noticed that foetal movements had begun to slow up 10 days after intrauterine transfusion, and because of this it was decided to induce labour.

Artificial rupture of the membranes was performed on $10 \mathrm{March}$, 11 days after the intrauterine blood transfusion. Labour began at once and lasted 4 hours 45 minutes; a female child weighing $6 \mathrm{lb}$. $(2,720 \mathrm{~g}$.) was born.

The general condition of the baby was good. The one mark of the needle prick, on the right side of the abdomen, was beginning to heal. Fig. 3 shows the place where the needle went through the abdomen. The baby's abdomen was soft and not distended. Her haemoglobin was $80 \%$ and four-fifths of this was donor blood and one-fifth foetal. The bilirubin was $6.5 \mathrm{mg} . / 100 \mathrm{ml}$. and two exchange transfusions were required in 36 hours to control the rising bilirubin level. At 2 months she was making satisfactory progress and appeared quite normal.

\section{Case 3}

Gravida-4 aged 29. Estimated date of delivery 20 May 1964 Blood group $\mathrm{O} r r$; husband's group $\mathrm{O} \mathrm{R}_{1} \mathrm{R}_{2}$. First pregnancy, 1957: a normal $8 \frac{1}{2}-\mathrm{lb}$. $\left(3,855-\mathrm{g}\right.$.) child at $41 \frac{1}{2}$ weeks. Second pregnancy, 1959: a normal $6 \frac{1}{2}$-lb. (2,950-g.) child at 40 weeks. Third pregnancy, 1962: a normal child at 40 weeks weighing $8 \mathrm{lb} .13 \mathrm{oz}$. (4,000-g.).

Present Pregnancy, 1964.-We saw this patient for the first time on 6 April, when she was $33 \frac{1}{2}$ weeks pregnant. The anti-D titre in albumin was $1: 4,000$. Amniocentesis was performed on 11 April. The amniotic fluid was blood-stained and the optical density at $450 \mathrm{~m} \mu$ was 0.149 . There was, however, a high peak at $415 \mathrm{~m} \mu$ and this may have accounted for part of the peak at $450 \mathrm{~m} \mu$. We estimated that the bilirubin peak was at least 0.1 . The pattern of pregnancies gave no reason to expect severe haemolytic disease and we were guided entirely by the amniotic fluid examination. The patient was a suitable subject for intrauterine blood transfusion. The foetal position could be easily assessed and we decided, with the agreement of the patient and her husband, to proceed with intrauterine blood transfusion.

This was performed on 13 April, when the patient was 34 weeks 5 days pregnant. We followed the technique used in Case 2 and only one abdominal $x$-ray film was taken before the operation, and a second one after introducing Urografin into the foetal abdomen. Foetal movements were noticeably more marked after the blood transfusion. The patient was discharged on the third day and readmitted for induction of labour on 24 April, 11 days after the blood transfusion. Labour lasted 10 hours 47 minutes, and the interval between induction and delivery was 39 hours. A living male infant was delivered at 36 weeks and was not weighed at birth. $\mathrm{His}$ condition was poor, with hepatosplenomegaly and a bilirubin level of $6.5 \mathrm{mg} . / 100 \mathrm{ml}$. His haemoglobin was $67 \%$, of which threefifths was donor blood and two-fifths foetal blood. His bilirubin level rose steeply and was not controlled until four exchange transfusions had been performed within 36 hours. Unfortunately he had a cardiac arrest during the second exchange transfusion and was resuscitated only after external cardiac massage.

From that time circulatory failure was apparent and was not improved by digoxin, oxygen, or subsequent exchange transfusion with attempted reduction in venous pressure. He collapsed and died on the third day. At post-mortem examination he weighed 7 lb. 3 oz. $(3,260$ g.). The heart showed marked bruising posteriorly. The abdomen was quite free of blood and its contents were normal and free from adhesions. The only evidence of interference found was a healing abrasion on the surface of the right lobe of the liver which might have been caused by the catheter. The abdominal skin showed no evidence of puncture, an indication that healing in the foetus is very rapid. The infant died from circulatory failure due to cardiac damage from external cardiac massage, given because of cardiac arrest during exchange transfusion. This latter is a recognized hazard which occurs in about $1 \%$ of exchange transfusions.

The foetal haemoglobin and bilirubin levels indicate clearly that this was a badly affected baby who would have been hydropic and probably stillborn under ordinary management.

\section{Case 4}

Gravida-2 aged 24. Estimated date of delivery 1 July 1964. Blood group $A$ rr; husband's group $A R_{1} R_{1}$. First pregnancy, 1962: a full-time, normal baby weighing $6 \mathrm{lb}$. $12 \mathrm{oz}$. (3,060 g.).

Present Pregnancy, 1964.-Early in pregnancy the antibody titre was $1: 2,000$, at 31 weeks it was $1: 4,000$. Amniocentesis was performed on 1 May at 31 weeks 2 days and the absorption peak of the liquor amnii at $450 \mathrm{~m} \mu$ was 0.126 . A week later, on $7 \mathrm{May}$, the optical density of amniotic fluid was 0.118 . These results indicated that the baby would be seriously affected.

Intrauterine blood transfusion was performed on 8 May, when the patient was 32 weeks 2 days pregnant. This particular blood transfusion was more difficult than the previous ones. The baby was in the antero-posterior position and the foetal abdomen was facing the maternal spine. The foetal legs were flexed and it was therefore very difficult to insert the needle into the foetal abdomen. After prolonged manipulation with the needle, which lasted possibly 15 minutes, the needle was finally introduced into the foetal abdominal cavity and the transfusion proceeded uneventfully.

The patient was observed in the ward for three days. Foetal movement increased on the third day. The patient had no bleeding, no abdominal pain, no temperature, and she was discharged home.

Six days after the blood transfusion she was seen in the antenatal clinic and complained of backache and lower abdominal discomfort suggesting the onset of labour. She was admitted to hospital and delivered of a male infant on 14 May, after a labour lasting 7 hours 20 minutes. The baby weighed $5 \mathrm{lb} .11 \mathrm{oz}$. $(2,580 \mathrm{~g}$.) $(33$ weeks maturity). The placenta weighed $1 \mathrm{lb} .4 \mathrm{oz}$. (565 g.), was healthy, and there was no evidence of a retroplacental clot. The general condition of the child was satisfactory, but oedematous. His haemoglobin level was $77 \%$, and half of the circulating blood was the donor's. His bilirubin level was $5 \mathrm{mg} . / 100 \mathrm{ml}$. and rose to $7 \mathrm{mg} . / 100 \mathrm{ml}$. within an hour. Exchange transfusion was performed and although the bilirubin was rising during the next day it became stationary on the third day and the baby did not need a further exchange transfusion.

What provoked the premature onset of labour six days after the blood transfusion is difficult to say, but it could have been due to bruising of the uterine muscle during the prolonged intrauterine manipulation.

\section{Case 5}

Gravida-3 aged 29. Estimated date of delivery 27 July 1964. Blood group $B R^{\prime \prime} r$; husband's group $A R_{1} r$. First pregnancy, 1961: normal pregnancy; normal delivery, healthy infant weighing 6 lb. 9 oz. $\left(2,975\right.$ g.) group $O R_{1}$ r. Second pregnancy, 1963: rhesus antibodies were present ; the titre rose from $1: 16$ to $1: 1,000$ during the pregnancy; labour was induced at 38 weeks; birth weight $5 \mathrm{lb} .7 \mathrm{oz}$. $(2,465 \mathrm{~g}$.). We are informed that this infant had haemolytic disease from which he died aged 10 days.

Present Pregnancy, 1964.-Throughout the pregnancy the albumin titre was $1: 2,000$ and the titre by the indirect Coombs technique was $1: 256$. Amniocentesis was performed on 25 May at 31 weeks. The liquor amnii showed an absorption peak at 450 $\mathrm{m} \mu$ of 0.35 (optical density). This was an exceptionally high peak suggesting that the baby would be severely affected and probably die in utero from hydrops.

The first intrauterine blood transfusion was performed on 28 May ( $31 \frac{1}{2}$ weeks of pregnancy) in the manner described in Case 2. The patient stayed in hospital for three days. Foetal movement increased noticeably on the third day after blood transfusion.

The patient was readmitted on 12 June and a second intrauterine

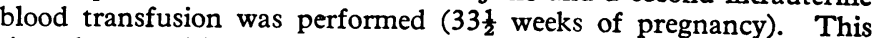
time she stayed in hospital under observation. The foetal movements increased on the second day after blood transfusion, but on the fifth and sixth days they were noticeably less active and this led 
us to induce labour. Artificial rupture of membranes was performed on 18 June ( $34 \frac{1}{2}$ weeks of pregnancy), six days after the second blood transfusion. Labour started immediately and a living male infant weighing $6 \mathrm{lb} .1 \mathrm{oz}$. (2,750 g.) was delivered within five hours of induction. At birth the baby was grossly oedematous and cyanosed but responded to resuscitation: his condition was only fair.

His cord blood haemoglobin level was $86 \%$, of which $3 \%$ was foetal haemoglobin, the bilirubin was $4.5 \mathrm{mg} . / 100 \mathrm{ml}$., the direct Coombs test was weakly positive, and free antibody to a titre of $1.1,000$ in albumin was present. By 18 hours the bilirubin had risen to $11 \mathrm{mg} . / 100 \mathrm{ml}$. and an exchange transfusion was performed giving $420 \mathrm{ml}$. and removing $390 \mathrm{ml}$. of blood. The infant remained in an incubator for three weeks. His condition improved as a result of digitalization and his weight fell to just under $5 \mathrm{lb}$. $(2,265 \mathrm{~g}$.) within a week. His progress was slow, but eventually feeding was established satisfactorily and he began to gain weight. His haemoglobin fell slowly and after four weeks reached $36 \%$. The circulating red cells were entirely adult and none of his own red cells could be found: this was not surprising as the antibody titre of his serum was still $1: 256$. Blood transfusion was given and may have to be repeated.

We cannot conceive that this infant would have been other than a stillborn hydrops foetalis without the intrauterine transfusions.

\section{Discussion}

One of the major problems in amniocentesis and intrauterine blood transfusion is the difficulty of finding the exact position of the placenta. Dippel and Brown (1940) have demonstrated that the placenta is situated with equal frequency on the posterior and anterior uterine walls. In most cases it seems that the placenta is facing the foetus and therefore in about $75-85 \%$ of cases it should be possible to introduce the needle near the foetal trunk and miss the placental site. In some cases when amniocentesis was performed the needle went through the placental site but caused neither retroplacental clot nor premature onset of labour. There seems to be little danger if a small-bore, sharp needle is used. We know, however, of one case in which a Tuohy needle passing through the placenta was followed by foetal death, due to haemorrhage from a damaged vein on the foetal aspect of the placenta.

Intrauterine manipulation of the Tuohy needle can be difficult and may have led to premature labour in Case 4. There is a risk of infection of the uterine cavity ; strict aseptic precautions should be maintained and prophylactic antibiotics given. Liley (1963b) chose to give penicillin and streptomycin into the amniotic cavity, but we preferred to omit this and instead give antibiotics systemically. There was no evidence of local or generalized infection in any of our patients.

Blind needling of the foetus may. damage tissues and we feel that the liver, which is usually large in these foetuses, is particularly at risk. In Case 1, where the liver was damaged, the lesion had clotted and would have been expected to heal. In Case 3 healing of the puncture wounds was so far advanced as to be almost complete. We feel that with gentle handling the risks to the foetus are not great.

Liley's technique of outlining the foetal gut is not successful when the infant cannot swallow. Although he felt that it was unlikely that an infant with hydrops could be rescued, our result in Case 1 shows that absorption of donor cells can occur in hydrops foetalis. In Case 5 the infant was hydropic at birth and almost devoid of foetal red cells. We cannot doubt that his life was saved by the two intrauterine transfusions at $31 \frac{1}{2}$ and $33 \frac{1}{2}$ weeks of pregnancy. The performance of the second transfusion was not made more difficult by the preceding one.

From Case 1 we also learnt that we could perform intrauterine transfusion without the preliminary use of Urografin in the amniotic cavity. This saves hours of waiting and reduces the radiation required. The injection of Urografin into the foetal abdominal cavity is essential as it gives the positive radiological evidence that the catheter is correctly situated.

It is well known that intraperitoneal haemorrhage leads to the formation of adhesions. Case 3 gave us the opportunity of examining the peritoneal cavity 15 days after intraperitoneal transfusion and we were pleased to discover that there were no adhesions, nor was there any macroscopic evidence of peritoneal reaction. It was also clear that the blood had been completely absorbed in 15 days.

We have long regarded a mother's observation of diminished and weak foetal movements as a bad prognostic sign in rhesus iso-immunization and we were happy to note significant improvement in foetal movements following the intrauterine transfusions in Cases 2, 3, 4, and 5.

Liley (1961, 1963a, 1963b) has claimed that amniocentesis and spectrophotometric assay are valuable in assessing the degree of disturbance. We have been guided by his charts in the selection of cases for intrauterine transfusion. Without this technique we would not have known that the disease was so severe in Cases 2, 3, 4, and 5 until the foetal movements had diminished, and then we would have been faced with premature hydropic infants and considered ourselves fortunate to have saved one of them. When we recall that the cord haemoglobin level of the infant's own cells was $16 \%, 27 \%, 37 \%$ and $3 \%$ in Cases 2, 3, 4, and 5, respectively, and that three of these infants survived and the other was lost from a separate cause, we can have little doubt about the value of intrauterine transfusion.

We do not have enough information to come to any definite conclusion but we suspect that, however safe this procedure may become, there will still be need for premature induction in these cases because of the increasing accumulation of bilirubin in the foetus.

\section{Summary}

Amniocentesis and spectrophotometric examination of the liquor amnii have been performed on antenatal patients with high titre $\mathrm{Rh}$ antibodies. If the optical density peak at $450 \mathrm{~m} \mu$ has indicated very severe haemolytic disease in the foetus then intraperitoneal transfusion has been given. Liley's technique for this has been modified by omitting the injection of Urografin and antibiotics into the amniotic cavity.

Four infants had one transfusion and one infant had two transfusions prior to delivery. One infant with hydrops foetalis was born too soon and could not be saved. Another infant had his haemolytic disease controlled but died after cardiac arrest during exchange transfusion. The other three have survived following exchange transfusion.

We are indebted to many members of the maternity and laboratory staff for their assistance, and particularly to our radiologists, Dr. N. D. W. Morrison and Dr. J. D. Irving, our paediatrician, Dr. Bruno Gans, and our resident pathologists, Dr. W. F. Whimster and Dr. R. Zeegen. Our thanks are also due to Mr. Alistair Gunn and Mr. A. E. R. Buckle for referring patients to us.

\section{REFERENCES}

Bevis, D. C. A. (1953). 7. Obstet. Gynaec. Brit. Emp., 60, 244. (1956). Ibid., 63, 68

Dippel, A. L., and Brown, W. H. (1940). Amer. F. Obstet. Gynec., 46, 986.

Liley, A. W. (1961). Ibid., 82, 1359

(1963a). Ibid., 86, 485

(1963b) Ibid., 86, 485. 1107.

McCrostie, H. H. (1964). Ibid., 1, 885. 